\title{
119 周期セル構造体のマルチスケール解析 Multiscale Analysis of Periodic Cellular Solids
}

\author{
正 大野 信忠（名古屋大） \\ Nobutada OHNO, Nagoya University, Chikusa-ku, Nagoya
}

Keywords: Cellular solids, Honeycombs, Microscopic bifurcation, Multiscale analysis

\section{1.はじめに}

ハニカムやフォーム（発泡体）に代表されるセル構造体 は，一般に比剛性が高いから，構造材料として注目されて いる.このような固体は微視構造を陽に有しており，その 力学的特性は大変與味深い.このため, セル構造体の力学 が，固体力学における最近のトピックスの一つとなってい る.

セル構造体に圧縮負荷を与えると，セル壁やセル辺に 座屈が生じる．このような座屈は微視的座屈と呼ばれ，こ れによってセル形状は複雑に変化する. 特に六角形八ニカ ムの面内圧縮では, 単軸圧縮と二軸圧縮の場合で異なる微 視的座屈モードが現れ ${ }^{(1)(2)}$ ，二軸圧縮下での微視的座屈モ 一ドは, 幾何学的に美しい対称性のゆえに分岐解析の観点 から魅力的である.また, 弾塑性セル構造体の場合, 微視 的座屈が巨視的変形の局所化を引き起こすことが実験で 観察されており ${ }^{(2)(3)}$ ，その解析はセル構造体の圧縮強度評 価上重要である.

セル構造体は微視構造が周期的である周期固体として 見る（あるいは理想化する）ことができるが，微視的座屈 が生じると，周期固体としての幾何学的対称性が失われる ことになり, 分岐問題として興味深い。またこの座屈は, 巨視的負荷のもとで生じる微視的座屈であるから，巨視的 変形と微視的変形という 2 種類の変形に関係するという 点で通常の構造物の座屈問題とは異なる。したがって, 周 期固体の微視的座屈を解くためには, 必然的にマルチスケ 一ルでの分岐を議論することなる.

講演者らは，周期セル構造体の分岐問題を解析するため， 更新 Lagrenge 形式での均質化理論を構筑するとともに分 岐条件を導出し，その応用として六角形八二カムや四角形 八ニカムの面内座屈挙動を解析してきた ${ }^{(4)-(8)}$. 本講演では, これらの研究成果について紹介することにより，周期セル 構造体の微視的座屈の特徵について述べる.

\section{2. 微視的分岐条件 ${ }^{(4)(6)}$}

周期的な微視構造を有する無限体 $\mathcal{B}$ を考え, その単位セ ルを $Y$ とする.このような物体に巨視的一様負荷を与える と, その微視的変形は初期には $Y$ 周期性を満足するが, 微 視的分岐が起きると， $Y$ 周期性が破れ，周期単位は $Y$ より 大きくなる. そこで, $k$ 個の単位セルからなる周期単位 $k Y$ を考え， $k Y$ の現配置に直交座標 $x_{i}(i=1,2,3)$ を設ける.
変位速度 $\dot{u}_{i}$ を巨視的成分 $\dot{u}_{i}^{0}$ と微視的成分 $\dot{u}_{i}^{*} に$ 分離する。 すなわち，

$$
\dot{u}_{i}=\dot{u}_{i}^{0}+\dot{u}_{i}^{*}
$$

ここで $\ddot{u}_{i}^{*}$ は，上述のような仮定のもとでは， $k Y$ 周期性を 満足する.このとき, $\mathrm{Hill}^{(9)}$ の提案した仮想仕事式は, 有 限変形に更新 Lagrenge 形式で次式のように搪張される.

$$
\left\langle\dot{\pi}_{j i} \delta \dot{u}_{i, j}\right\rangle=\dot{\Pi}_{j i} \delta \dot{u}_{i, j}^{0}
$$

ここで， $\dot{\pi}_{j i}$ と $\dot{\Pi}_{j i}$ はそれぞれ微視的および巨視的公称応力 速度を示し，〈〉は周期単位 $k Y$ に関する体積平均を表す. また， $\delta \dot{u}_{i}$ は $\dot{u}_{i}$ の任意の変分を示し， $\delta \dot{u}_{i . j}^{0}=\left\langle\delta \dot{u}_{i, j}\right\rangle$ が成り 立つ，なお( ), は， $x_{i}$ に関する微分を表す.

微視的構成式として次式を考える.

$$
\dot{\pi}_{j i}=l_{i j k l} \dot{u}_{k, l}
$$

上式と式(1)を式(2)に代入すると，巨視的構成式と微視的 速度場決定問題がそれぞれ

$$
\begin{aligned}
& \dot{\Pi}_{j i}=\left\langle l_{j i k l}\left(\dot{u}_{k, l}^{0}+\dot{u}_{k, l}^{*}\right)\right\rangle \\
& \left\langle l_{i j p q} \dot{u}_{p, q}^{*} \delta \dot{u}_{i, j}^{*}\right\rangle=-\dot{u}_{k, l}^{0}\left\langle l_{i j k l} \delta \dot{u}_{i, j}^{*}\right\rangle
\end{aligned}
$$

のように導かれる。この結果, 微視的分岐問題は

$$
\left\langle l_{i j k l} \phi_{k, l}^{(r)} \delta \dot{u}_{i, j}^{*}\right\rangle=0, r=1,2, \ldots, m
$$

と定式化される。ここで， $\phi_{i}^{(r)}$ は固有モードを示し， $m$ は 分岐の多重度である. また $\delta \ddot{u}_{i}^{*}$ は, $k Y$ 周期性を満足する任 意の速度場である. 式(6)により求められる $\phi_{i}^{(r)}$ は, 次式の ような直交性を満たすことが示される。

$$
\left\langle l_{i j k l} \phi_{i, j}^{(r)}\right\rangle=0, r=1,2, \ldots, m
$$

式(4)と(7)より， $\phi_{i}^{(r)}$ は微視的分岐点での巨視的変化速度 に影響を及ぼさないことがわかる.したがって，微視的分 岐点での固有モードは巨視的速度と独立に求められるか ら，比較体の概念 ${ }^{(10)}$ に基づく弾塑性体の分岐後解析が容易 となる.

\section{3. 六角形ハニカムの面内座屈 ${ }^{(4)-(6)}$}

すでに述べたように，周期構造体に微視的分岐が生じる と，対称性が破られるため，単位セルが周期単位でなくな る可能性がある. そこで, 複数の単位セルからなるセル集 合体 $k Y$ に関して周期性が成り立つと仮定し，六角形八二 力ムの面内座屈挙動を解析した. 六角形八二カムは, 巨視 的な面内二軸応力 $\Sigma_{11}, \Sigma_{22}$ を受けるとした（図 1).

まず, 弾性ハニカムを, セル壁の長さ $l$, 厚さ $h$, ヤング 率 $E$, ポアソン比 $v$ として解析した。 この場合は, $2 \times 2$ 個 


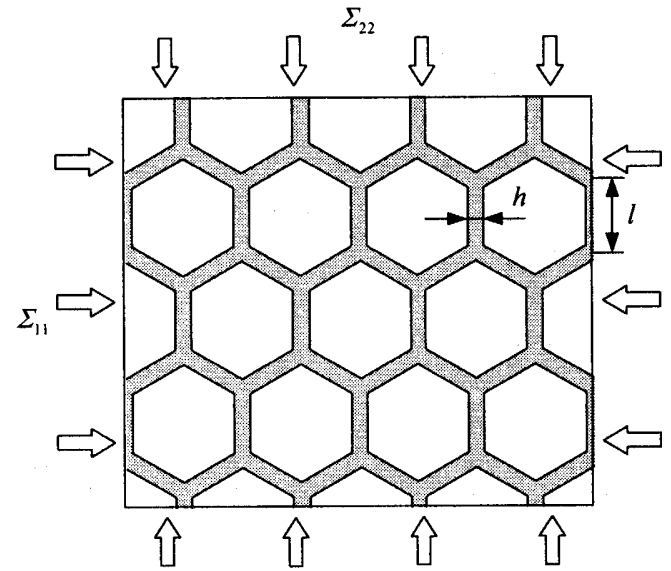

Fig. 1. Hexagonal honeycombs subject to in-plane biaxial compression.

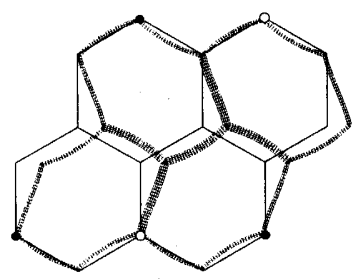

(a) $\phi^{(00)}$

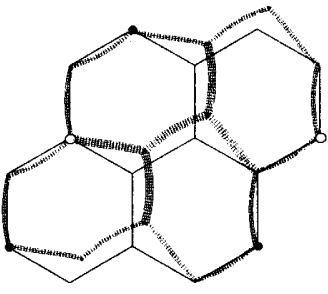

(b) $\phi^{(-30)}$

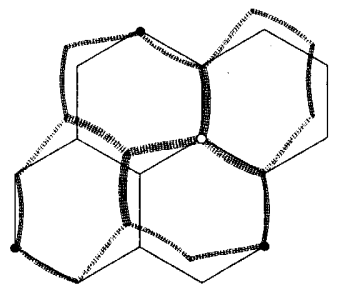

(c) $\phi^{(30)}$
Fig. 2. Three eigenmodes of $Y_{2 \times 2}$ of elastic hexagonal honeycombs subject to in-plane equi-biaxial compression.

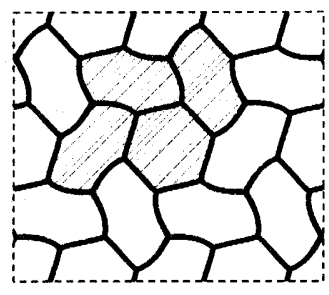

(a) $\phi=\phi^{(90)}+\phi^{(-30)}+\phi^{(30)}$

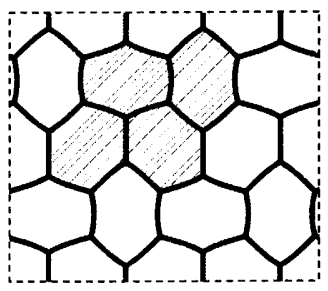

(b) $\phi=\phi^{(-30)}+\phi^{(30)}$
Fig. 3. Combined eigenmodes of elastic hexagonal honeycombs.

のユニットセルからなる周期単位 $Y_{2 \times 2}$ を考えれば十分であ り，等二軸圧縮負荷 $\left(\Sigma_{11}=\Sigma_{22}<0\right)$ では 3 重分岐が生じ た.このように等二軸圧縮負荷のもとで 3 重分岐が生じる のは, 次の理由による. 六角形ハニカムは三つのセル壁方 向を有しているが，等二軸圧縮負荷では三つのセル壁方向 に等しい圧縮荷重がかかる．このため，三つのセル壁方向

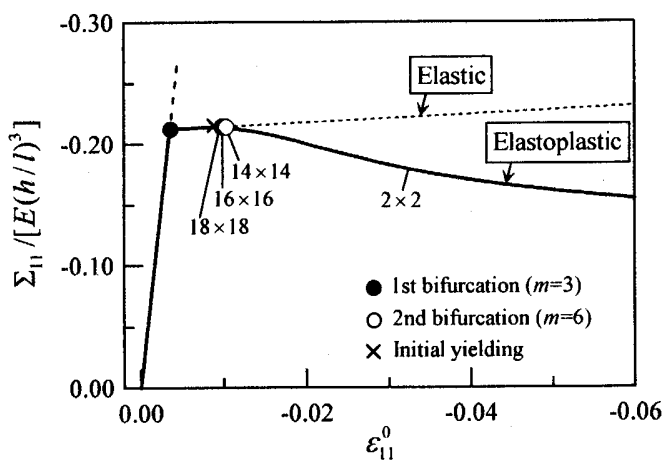

Fig. 4. Macroscopic stress-strain relation of an elastoplastic hexagonal honeycomb under in-plane equi-biaxial compression.

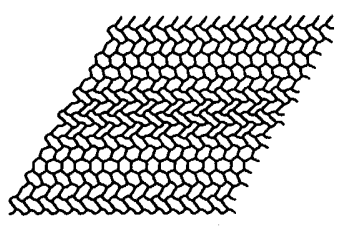

(a) $\phi^{(90)}$

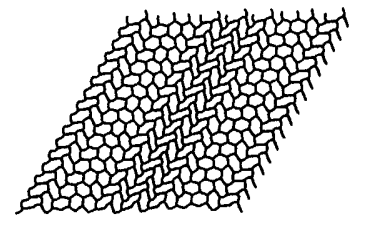

(b) $\phi^{(-30)}$

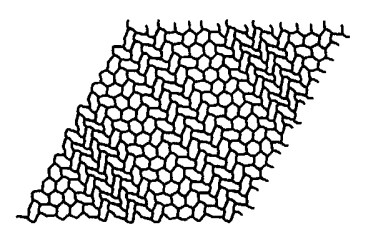

(c) $\phi^{(30)}$

Fig. 5. Three long-wave eigenmodes of $Y_{16 \times 16}$ of elastoplastic hexagonal honeycombs subject to in-plane equi-biaxial compression.

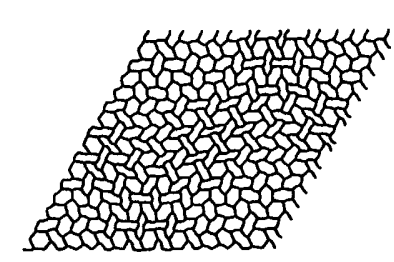

(a) $\phi=\phi^{(90)}+\phi^{(-30)}+\phi^{(30)}$

Fig. 6. Combined long-wave eigenmodes of elastoplastic hexagonal honeycombs under in-plane equi-biaxial compression.

のそれぞれに同時に微視的座屈が起き得るから，3 重分岐 となる.この結果, 等二軸圧縮負荷では, 三つの独立な微 視的座屈モード $\phi^{(90)}, \phi^{(-30)}, \phi^{(30)}$ が存在することになる(図 2)。これら三つの座屈モードは, 各セル壁方向の単軸座屈 モードを表す。これらが同時に生じるとして $\phi=\phi^{(90)}+\phi^{(-30)}+\phi^{(30)}$ を求めると, 図3(a)に斜線で示した変

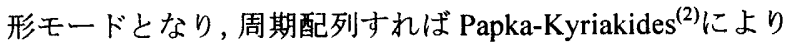
観察された花状座屈モードが得られる。また， $\phi^{(-30)}$ と中 $\phi^{(30)}$ だけがアクティブになるとすれば，Gibson-Ashby(1)によっ て報告された二軸圧縮座屈モードとなる [図 3(b)]. なお Saiki ら ${ }^{(11)}$ は, 花状座屈を群論的分岐理論により詳細に調 べている.

次に, 弾塑性ハニカムの場合は, 第 1 分岐点後に第 2 分 
岐が生じたが，第 2 分岐点は第 1 分岐点とは異なり周期単 位の大きさに依存した，例えば等二軸圧縮変形では，周期 単位を $Y_{14 \times 14}$ 以上にとったときに第 2 分岐が起き, 周期単 位を $Y_{18 \times 18}$ とした場合はセル壁が初期降伏した直後に第 2 分岐が生じた（図 4). 周期単位を $Y_{16 \times 16}$ とした場合の第 2 分岐点での三つの基本分岐モード $\phi^{(90)} ， \phi^{(-30)} ， \phi^{(30)}$ を図 5(a)〜 (c)に示す.これらは三つのセル壁方向への座屈モ一 ドであり, 重盢して $\phi=\phi^{(\mathscr{( N )})}+\phi^{(-30)}+\phi^{(30)}$ を求めたところ 図6(a)に示すような分岐モードとなった.この図を見ると， 第 2 分岐点での微視的座屈は巨視的一様に進行せず, 巨視 的局所化を伴うことがわかる．このような巨視的局所化は， 実験でも観察されている(2). なお，重畳する際に ${ }^{(30)}$ の符 号を変えたところ図 6(a)とは異なる分岐モードが得られ [図 6(b)]，基本分岐モードの符号に関して非対称である ことがわかった.

図 5(a)〜(c)に示した三つの基本分岐モードの周期長さ は, セル数で 16 である.このように周期長さの長い分岐 は長波長分岐と呼ばれ，周期長さの十分に長い長波長分岐 は巨視的不安定点の直後に生じることが知られている ${ }^{(12)}$. ここで巨視的不安定点とは，巨視的な応力増分とひずみ増 分の関係に分岐が生じる点である.上述の等二軸圧縮変形 の場合，セル壁の初期降伏後に巨視的軟化が生じると同時 に巨視的不安定条件が満足され，周期単位 $Y_{18 \times 18}$ による第 2 分岐点が検出された。このことより，巨視的不安定と長 波長の微視的分岐との関係が均質化理論により合理的に 解析されることがわかる。

\section{4. 四角形ハニカムの面内座届 ${ }^{(7)(8)}$}

触媒担体として使用される四角形八二カムは, 触媒担体 ケース内でかなりの面内圧縮負荷を受けるから，その面内 座屈荷重の評価は重要である.

四角形八二カ厶の面内座屈挙動を解析するため, 図 7 に 示すようなセル集合体 $Y_{2 \times 2}, Y_{4 \times 4}, \ldots$ を周期単位にとり解 析した。 セル壁（長さ $l$, 厚さ $h$ ) は弾性体（ヤング率 $E$, ポアソン比 v) とし, 四角形八二カムは巨視的応力 $\Sigma_{11}, \Sigma_{22}$ を受けるとした，この結果, 微視的分岐は周期単位に著し く依存し, 周期単位を大きくとるほど座屈荷重は減少した (図 8).周期単位として $Y_{2 \times 2}$ と $Y_{16 \times 16}$ をとったときの単軸 圧縮座屈モードを図 9(a), (b)に，また二軸圧縮下での微視 的分岥点を図 10 に示す. 図 10 から， $Y_{16 \times 16}$ を周期単位に

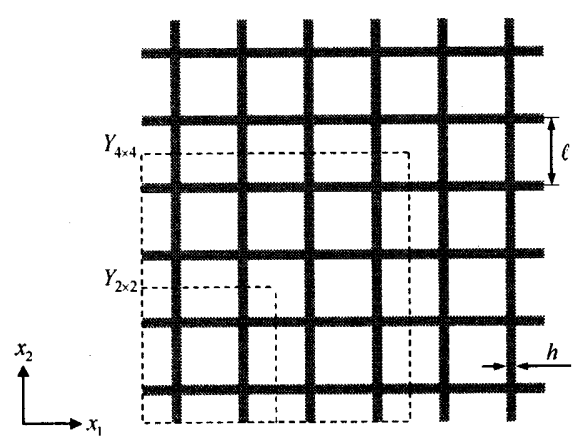

Fig. 7. Periodic units of square honeycombs.

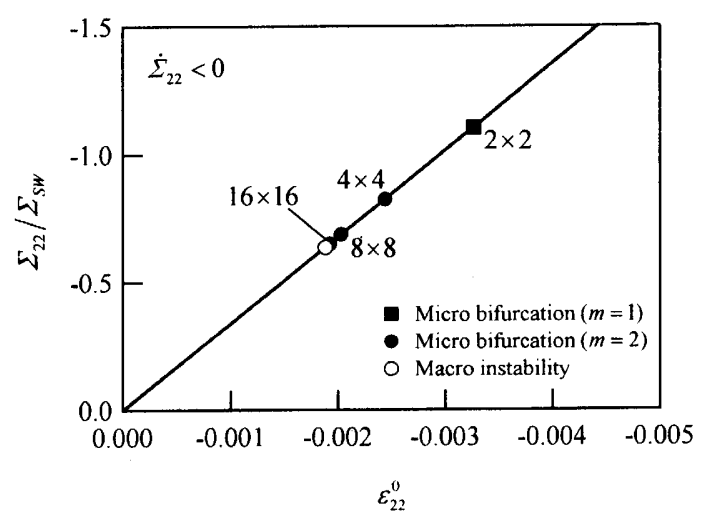

Fig. 8. Microscopic bifurcation and macroscopic instability points of an elastic square honeycomb under in-plane uniaxial compression.

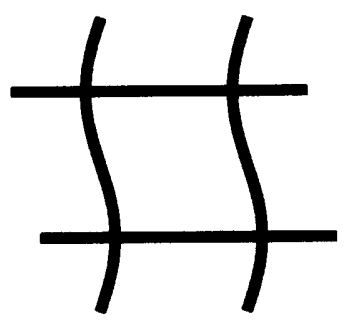

(a) $Y_{2 \times 2}$

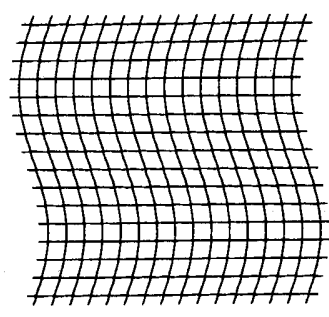

(b) $Y_{16 \times 16}$
Fig. 9. Buckling modes of elastic square honeycombs under in-plane uniaxial compression.

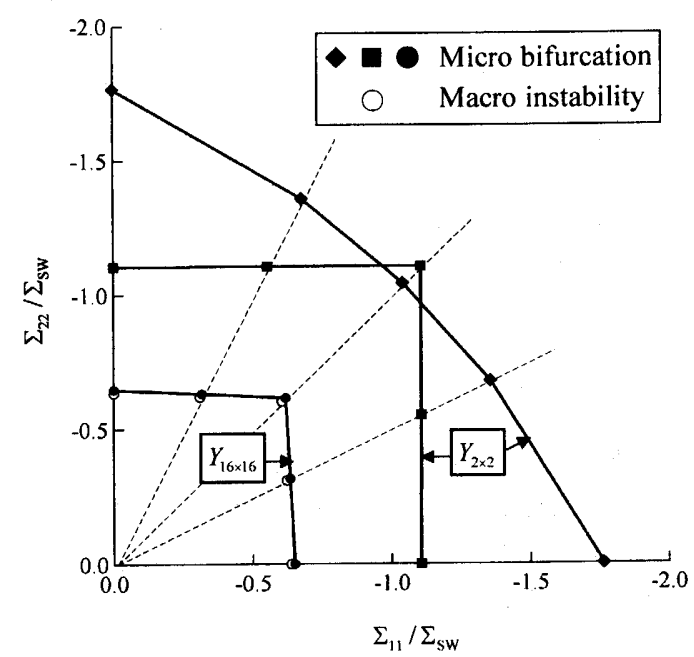

Fig. 10. Buckling stresses of elastic square honeycombs subject to in-plane biaxial compression.

とった場合の座屈荷重は $Y_{2 \times 2}$ による座屈荷重（短波長座屈 荷重 $\Sigma_{\mathrm{sw}}$ ）に比べて $40 \%$ ほど低くなること，また $Y_{16 \times 16}$ に よる微視的分岐点は巨視的不安定点とほとんど一致する ことがわかる.つまり，面内圧縮負荷を受ける四角形八二 カ厶では，第 1 分岐点で長波長分岐が生じる.これは，3 章で述べた六角形八ニカムの第 1 分岐点とは異なる特徵で 


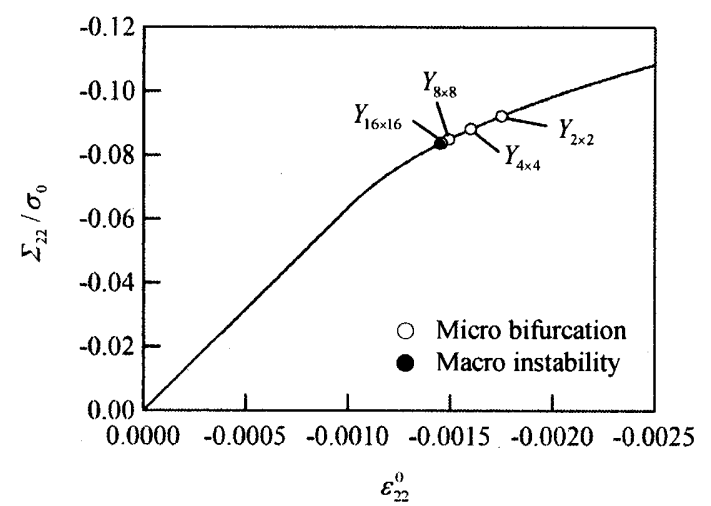

Fig. 11. Microscopic bifurcation and macroscopic instability points of an elastoplastic square honeycomb under in-plane uniaxial compression.

ある。

四角形八ニカムの面内座屈荷重は, これまで短波長座屈 荷重 $\Sigma_{\mathrm{sW}}$ を用いて評価されてきた。しかし上述のように, 第 1 分岐点で長波長分岐が生じ，その分岐荷重 $\Sigma_{\mathrm{LW}}$ は $\Sigma_{\mathrm{SW}}$ より 40\%ほど低くなる．そこで，巨視的不安定条件を詳細 に検討することにより $\Sigma_{\mathrm{LW}}$ を解析的に求めたところ,

$$
\Sigma_{\mathrm{LW}}=\left[E / 2\left(1-v^{2}\right)\right](h / l)^{3}
$$

という簡単な公式が導かれ, 均質化理論に基づく有限要素 解析結果とよく一致した。このように簡単な公式が，均質 化理論によるマルチスケール解析の結果として導かれた ことは意義深い.

四角形ハニカムのセル壁が弾塑性材料である場合も, 微 視的分岐は，図 11 に示すように周期単位に依存した。こ の解析では, セル壁の初期降伏忍力を $\sigma_{0}$ とし, その忘力一 ひずみ曲線はべき乗則に基づくとした，図 11 を見ると， $Y_{2 \times 2}$ と $Y_{16 \times 16}$ による微視的分岐荷重の違いは $10 \%$ 程度であ り，弾性の場合に比べて僅かである。したがって，微視的 分岐荷重の周期単位依存性は, セル壁の塑性変形により目 立たなくなることがわかる.

\section{5. おわりに}

本講演では，基本的な周期セル構造体である六角形八二 カムと四角形八二カムの面内座屈挙動を均質化理論によ り解析した結果を示した。これらの解析例を紹介すること により，均質化理論に基づくマルチスケール解析法が微視 的変形と巨視的変形の関係を議論するために有効である ことを述べた．今後このような解析法は, さらに複雑な周 期セル構造体・構造物に適用されると期待される.

\section{文献}

(1) Gibson, L. J. and Ashby, M. F., Cellular Solids: Structure and Properties, 2nd ed. (1997), Cambridge University Press.

(2) Papka, S. D. and Kyriakides, S., Biaxial crushing of honeycombs - Part I: experiments. Int. J. Solids Struct., 36 (1999), 4367-4396.

(3) Zhu, H. X. and Mills, N. J., The in-plane non-linear compression of regular honeycombs. Int. J. Solids Struct., 37 (2000), 1931-1949.

(4) Ohno, N., Okumura, D. and Noguchi, H., Microscopic symmetric bifurcation condition of cellular solids based on a homogenization theory of finite deformation. J. Mech. Phys. Solids, 50 (2002), 1125-1153.

(5) Okumura, D., Ohno, N. and Noguchi, H., Post-buckling analysis of elastic honeycombs subject to in-plane biaxial compression. Int. J. Solids Struct., 39 (2002), 3487-3503.

(6) Okumura, D., Ohno, N. and Noguchi, H., Elastoplastic microscopic bifurcation and post-bifurcation behavior of periodic cellular solids. J. Mech. Phys. Solids, 52 (2004), 641-666.

(7) Ohno, N., Okumura, D. and Niikawa, T., Long-wave buckling of elastic square honeycombs subject to in-plane biaxial compression. Int. J. Mech. Sci., 46 (2004), 1697-1713.

(8) Erami, K., Ohno, N. and Okumura, D., Long-wave in-plane buckling of elastoplastic square honeycombs. Int. J. Plasticity, (submitted).

(9) Hill, R., The essential structure of constitutive laws for metal composites and polycrystals. J. Mech. Phys. Solids, 15 (1967), 79-95

(10) Hutchinson, J.W., Post-bifurcation behavior in the plastic range. J. Mech. Phys. Solids, 21 (1973), 163-190.

(11) Saiki, I., Ikeda, K. and Murota, K., Flower patterns appearing on a honeycomb structure and their bifurcation mechanism. Int. J. Bifurcation Chaos, 15 (2005), 497-515.

(12) Geymonat, G., Müller, S. and Triantafyllidis, N., Homogenization of nonlinearly elastic materials, microscopic bifurcation and macroscopic loss of rank-one convexity. Arch. Ration. Mech. Anal., 122 (1993), 231-290. 